\title{
Has COVID19 derailed Bhutan's national malaria elimination goal? A commentary
}

\author{
Kinley Penjor ${ }^{1 *} \mathbb{0}$, Tobgyal ${ }^{1}$, Tandin Zangpo ${ }^{2}$, Archie C. A. Clements ${ }^{3,4}$, Darren J. Gray ${ }^{5}$ and Kinley Wangdi ${ }^{5}$
}

\begin{abstract}
The COVID-19 pandemic has resulted in massive global disruptions with considerable impact on the delivery of health services and national health programmes. Since the detection of the first COVID-19 case on 5th March 2020, the Royal Government of Bhutan implemented a number of containment measures including border closure and national lockdowns. Against the backdrop of this global COVID-19 pandemic response, there was a sudden surge of locally-transmitted malaria cases between June to August 2020. There were 20 indigenous cases (zero Plasmodium falciparum and 20 Plasmodium vivax) from a total of 49 cases (seven P. falciparum and 42 P. vivax) in 2020 compared to just two from a total of 42 in 2019 . Over $80 \%$ of the cases were clustered in malaria endemic district of Sarpang. This spike of malaria cases was attributed to the delay in the delivery of routine malaria preventive interventions due to the COVID-19 pandemic. As a result, Bhutan is unlikely to achieve the national goal of malaria elimination by 2020.
\end{abstract}

\section{Background}

The current coronavirus disease (COVID-19) has resulted in massive global disruptions with major impacts in health service delivery [1]. Bhutan recorded its first confirmed case of COVID-19 on $5^{\text {th }}$ March 2020 [2], with a total of 356 reported cases with no deaths at the time of writing. Following the first case of COVID-19, the Government of Bhutan initiated a number of containment measures. These included vigorous contact tracing, testing and treatment (3Ts) of the cases, closing its international borders and restricting mass gatherings including closing schools and markets, limiting movements, temporarily discontinuing non-essential services, and a mandatory 21-day quarantine for all returning travellers and primary close contacts. In addition, a 21-day nationwide lockdown was initiated on August 11, 2020 following local transmission of COVID-19. In the last decade, Bhutan pursued a successful and sustained malaria elimination programme. This has led to a low incidence of

\footnotetext{
${ }^{*}$ Correspondence: kinleyp@health.gov.bt

${ }^{1}$ Vector-Borne Disease Control Programme, Department of Public Health, Ministry of Health, Gelephu, Bhutan

Full list of author information is available at the end of the article
}

malaria that is compatible with elimination programme [3]. The malaria cases have dwindled to just two indigenous cases in 2019 [4]. In line with the World Health Organization (WHO) Global Technical Strategic (GTS 2016-30) and regional action plan for malaria elimination by 2030 , Bhutan planned to eliminate malaria by 2020 [ 5 , 6]. The key interventions implemented by the programme are three-yearly rounds of mass distribution of long-lasting insecticidal nets (LLIN), focal indoor residual spraying (IRS), prompt diagnosis and case management, and case-based surveillance and response. The last mass distribution of LLINs in the malaria transmission districts was done in 2017. Currently, active malaria transmission foci are confined mainly to southern districts along the international border with India $[7,8]$.

\section{Main text}

We report of a sudden surge of malaria cases in 2020 against the backdrop of the global COVID-19 pandemic. This cluster of cases related closely in space and time threatens to derail the national elimination goal. As of 30th September 2020, there were 49 cases as compared to 2019, which reported a total of 42 cases with two indigenous transmissions. The cases in July (21) and

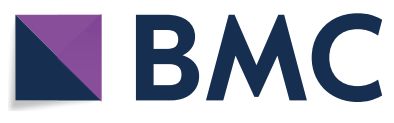

c) The Author(s) 2021. This article is licensed under a Creative Commons Attribution 4.0 International License, which permits use, sharing, adaptation, distribution and reproduction in any medium or format, as long as you give appropriate credit to the original author(s) and the source, provide a link to the Creative Commons licence, and indicate if changes were made. The images or other third party material in this article are included in the article's Creative Commons licence, unless indicated otherwise in a credit line to the material. If material is not included in the article's Creative Commons licence and your intended use is not permitted by statutory regulation or exceeds the permitted use, you will need to obtain permission directly from the copyright holder. To view a copy of this licence, visit http://creativeco mmons.org/licenses/by/4.0/. The Creative Commons Public Domain Dedication waiver (http://creativecommons.org/publicdomain/ zero/1.0/) applies to the data made available in this article, unless otherwise stated in a credit line to the data. 
August (10) in 2020 were above the mean monthly trend for the last five years (2015-2019). A case-based investigation and classification is undertaken by the programme in line with the recommendations of the World Health Organization (WHO) [9]. The 'indigenous' case is defined as malaria infection which is acquired within the country, whereas 'introduced' is defined as locally acquired case with strong epidemiological link to the imported case and 'imported' refers to a case whose origin can be traced to an area of transmission outside Bhutan with a travel history to a malaria-endemic area outside Bhu$\tan$ within one month before the diagnosis of malaria [9, $10]$. Based on those criteria, $82 \%(40 / 49)$ were classified as locally-transmitted cases (20 indigenous and 20 introduced cases). All malaria cases excepting one reported here were captured through the national surveillance system which is a passive reporting system. All febrile cases reporting to the health facilities are tested for malaria by using either rapid diagnostic tests (RDT) or microscopy. Eight-six percent (42/49) of the total cases were Plasmodium vivax, and spatially, more than $80 \%$ of cases were recorded in Sarpang District (39/49 reported in 2020) (Fig. 1). Sarpang is one of the remaining active malaria transmission foci in Bhutan.

This spike of malaria cases in Sarpang District is attributed in part due to disruptive effects of the COVID-19 pandemic on the delivery of routine malaria preventive interventions $[11,12]$. First, the planned mass distribution of LLINs, a core programme intervention, earlier this year was delayed. This delay was partly due to the freight disruptions affecting the smooth and timely supply of critical anti-malarial commodities and logistics, caused by COVID-19 pandemic. The core vector control interventions such as first rounds of IRS, health education, follow up of regular LLINs use, and vector surveillance is scheduled annually in March-April. However, the mass LLIN distribution was implemented only towards the end of May in Sarpang, after the beginning of malaria transmission season. Additionally, despite an already limited number of malaria staff, some malaria field workers were engaged in the COVID-19 pandemic response programmes rolled out by health facilities and districts.

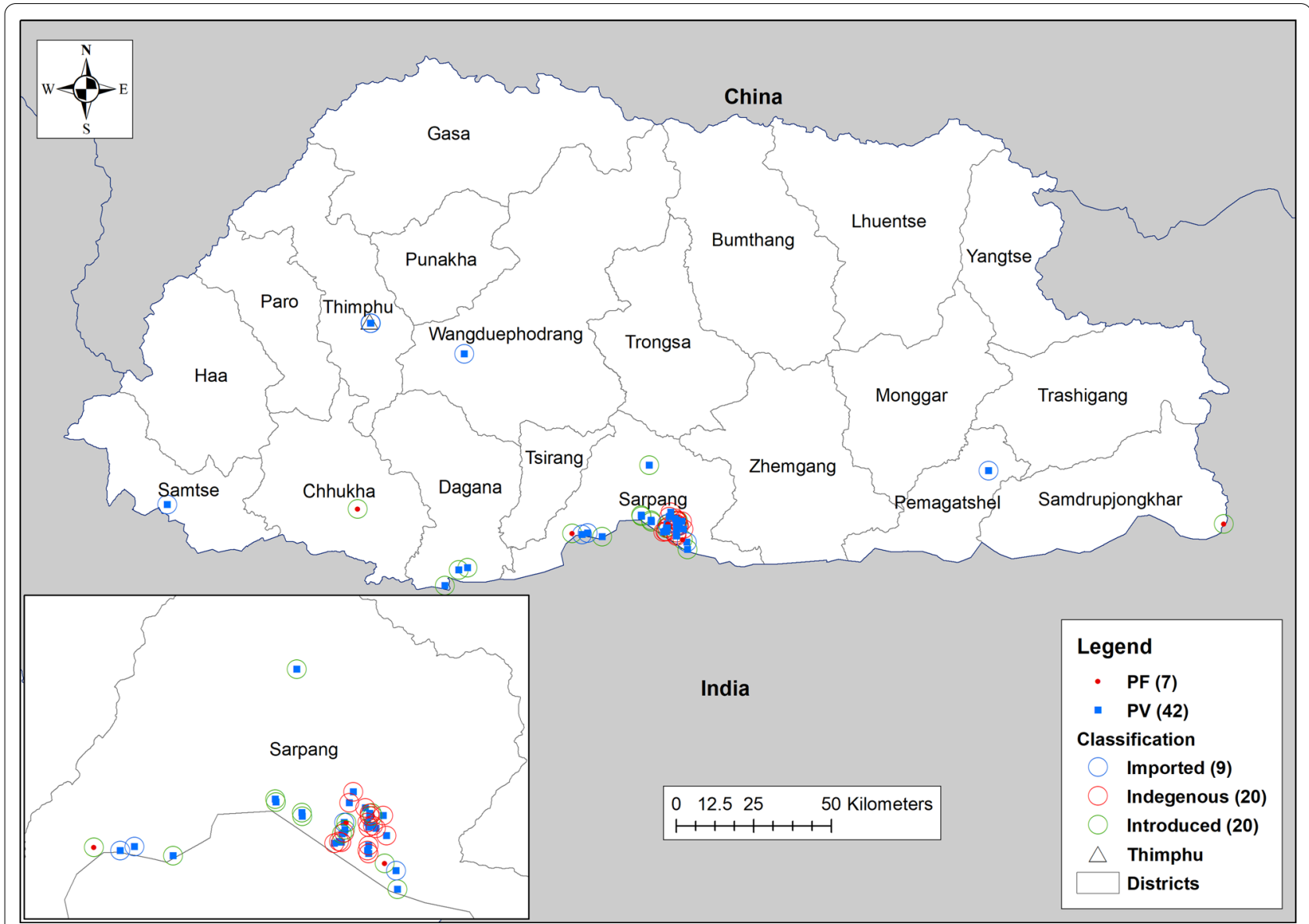

Fig. 1 Malaria case distribution by species and case classification in Bhutan in 2020. (The map was produced by authors using Quantum GIS, QGIS Development Team (2019), QGIS Geographic Information System, Open Source Geospatial Foundation Project (http://qgis.osgeo.org) 
This has been linked to delays in malaria surveillance and response activities such as follow up of index cases, which is an integral component of the malaria elimination programme.

The future prevention efforts to avert similar upset in public health programme calls for advance preparedness and contingency planning to effectively manage and respond to such large scale emergencies through a wellintegrated and coordinated operational framework of national emergency planning. The delays and disruptions could be minimized through the strengthening of community-based approaches that facilitates continued delivery of essential services including LLIN distribution and IRS, and arrangements to support health care-seeking for fever such as volunteer assisted travel from the place of residence to health centres. Similarly, the health facility level emergency operational plan should be established, regularly reviewed and embedded within the ambit of national health emergency response framework. The operational plans for the delivery of essential programme services should form a key component of any future pandemic preparedness and response planning.

\section{Conclusion}

This experience from Bhutan highlights the impact of COVID-19 in the delivery of routine public health services. This unforeseen crisis will jeopardize the national goal of malaria elimination in Bhutan by 2020 .

\section{Abbreviations}

COVID19: Coronavirus Disease 2019; WHO: World Health Organization; VDCP: Vector-borne Disease Control Programme; LLIN: Long-Lasting Insecticidal Nets; IRS: Indoor Residual Spraying; GTS: Global Technical Strategy.

\section{Acknowledgements}

The authors would like to thank the VDCP, Bhutan for allowing the use of surveillance data and Ministry of Health, Bhutan for approving this study.

\section{Authors' contributions}

KP and KW conceived and drafted the manuscript. All authors contributed to the contents and critically reviewed the manuscript. All authors read and approved the final manuscript.

\section{Funding}

No funding was required for this study.

\section{Availability of data and materials}

The data is available from the corresponding author on reasonable request.
Consent for publication

The author takes full responsibility for publication.

\section{Competing interests}

The author(s) declare that they have no competing interests.

\section{Author details}

${ }^{1}$ Vector-Borne Disease Control Programme, Department of Public Health, Ministry of Health, Gelephu, Bhutan. ${ }^{2}$ Department of Public Health, Communicable Disease Division, Ministry of Health, Thimphu, Bhutan. ${ }^{3}$ Faculty of Health Sciences, Curtin University, Perth, Australia. ${ }^{4}$ Telethon Kids Institute, Nedlands, Perth, Australia. ${ }^{5}$ Department of Global Health, College of Health and Medicine, Research School of Population Health, Australian National University, Acton, ACT 2601, Australia.

Received: 12 November 2020 Accepted: 19 December 2020 Published online: 06 January 2021

\section{References}

1. Júnior JG, de Sales JP, Moreira MM, Pinheiro WR, Lima CKT, Neto MLR. A crisis within the crisis: the mental health situation of refugees in the world during the 2019 coronavirus (2019-nCoV) outbreak. Psychiatry Res. 2020;288:113000

2. LeVine S, Dhakal GP, Penjor T, Chuki P, Namgyal K, Tshokey, et al. Case report: The First Case of COVID-19 in Bhutan. Am J Trop Med Hyg. 2020;102:1205-7.

3. Wangchuk S, Gyeltshen S, Dorji K, Wangdi T, Dukpa T, Namgay R, et al. Malaria elimination in Bhutan: asymptomatic malaria cases in the Bhutanese population living in malaria-risk areas and in migrant workers from India. Rev Inst Med Trop São Paulo. 2019;61:e52.

4. Vector-Borne Disease Control Programme. National malaria surveillance database. Ministry of Health Bhutan; 2020.

5. VDCP. Bhutan National Malaria Strategic Plan 2015-2020. Ministry of Health Bhutan, 2015.

6. WHO. Regional Action Plan 2017-2030 towards Zero malaria-free South East Asia Region. Geneva: World Health Organization; 2017.

7. Wangdi K, Xu Z, Suwannatrai AT, Kurscheid J, Lal L, Namgay R, et al. A spatio-temporal analysis to identify the drivers of malaria transmission in Bhutan. Sci Rep. 2020;10:7060.

8. Wangdi K, Banwell C, Gatton ML, Kelly GC, Namgay R, Clements AC. Malaria burden and costs of intensified control in Bhutan, 2006-14: an observational study and situation analysis. Lancet Glob Health. 2016;4:e336-343.

9. WHO. Disease Surveillance for Malaria Elimination: an operational manual. Geneva: World Health Organization; 2012.

10. Vector Borne Disease Control Programme. Guidelines for Malaria surveillance and response Bhutan 2018. Minsitry of Health Bhutan; 2018.

11. Ansumana R, Sankoh O, Zumla A. Effects of disruption from COVID-19 on antimalarial strategies. Nat Med. 2020;26:1334-6.

12. Ranaweera P, Wickremasinghe R, Mendis K. Preventing the re-establishment of malaria in Sri Lanka amidst the COVID-19 pandemic. Malar J. 2020;19:386.

\section{Publisher's Note}

Springer Nature remains neutral with regard to jurisdictional claims in published maps and institutional affiliations. 